\title{
Da política do pior ao melhor das utopias e à globalização do terror
}

\section{RESUMO}

Nesta entrevista, concedida em Paris em março de 2001, e complementada por e-mail após os acontecimentos de 11 de setembro, Paul Virilio, especialista em novas tecnologias da comunicação, desmonta 0 que considera ser as ilusões do ciberespaço e defende um novo investimento intelectual e social na realidade das utopias.

\section{ABSTRACT}

In this interview, which took place in Paris, in march of 2001, and which was later updated by e-mail, after the events of September 11, Paul Virilio, a philosopher who is an expert on the new technologies of communication, deconstructs what he considers to be some ilusions about cyberspace, at the same time that he advocates a new intelectual and social investment on the reality of utopies.

PALAVRAS-CHAVE (KEY WORDS)

- Novas tecnologias (New technologies)

- Comunicação (Communication)

- Ciberespaço (Cyberspace)
FILÓSOFo, URBANISTA, ARQUITETO, polemista, ex-diretor da Escola de Arquitetura de Paris, Paul Virilio, nascido em 1932, na capital francesa, é um antigo combatente das causas que nunca envelhecem e têm valor universal. Professor universitário, autor de vários livros, entre os quais A Arte do motor, Velocidade e política e Internet, a política do pior, colaborador do jornal Le Monde Diplomatique, Virilio dirige a coleção "Espaços de crítica" na editora Galilée.

Para ele, estar na contramão das modas intelectuais é uma obrigação dos pensadores autônomos e engajados nas lutas por um mundo melhor. Paul Virilio considera-se um homem de esquerda, um democrata e um defensor do melhor das utopias políticas. Em outras palavras, um crítico do neoliberalismo, do capitalismo, da globalização e do novo império da técnica em todas as suas formas, do ciberespaço à automação. Original, entende que o problema central das novas tecnologias da comunicação não está na produção de isolamento, mas, ao contrário, na eliminação do espaço de separação entre as pessoas.

Enquanto se dissemina a idéia de que o pensamento francês acabou, conforme uma crítica que não consegue dissimular o seu ressentimento, além de legitimar o pensamento único de matriz norte-americana que, paradoxalmente, pretende atacar, Virilio é mais uma ilustração de que a "decadente" França continua, teimosamente, a resistir, a vicejar e a renovar o seu capital simbólico internacional.

Revista FAMECOS - O senhor tem 
tratado, com freqüência, de um tema que se torna moda entre os intelectuais, as novas tecnologias da comunicação. Internet já é a realização de um sonho ou permanece uma ilusão?

Paul Virilio - Uma ilusão. Não creio que os sonhos sejam ilusões. Sem ser freudiano, penso que os sonhos têm uma potência de condicionamento do ser. Internet é uma ilusão tecnocientífica. É a ilusão da cibernética. Não se pode pensar a internet sem o advento da cibernética. A informática é uma coisa; a cibernética, outra. A colocação da informática em rede desemboca na cibernética, ou seja, em sistemas de condicionamento radicalmente terroristas num certo tempo. Não neste momento. Mas já existe a tentação de usá-los para controle social.

Portanto, para mim, internet é uma ilusão que está desabando. Não só por causa da queda da Nasdaq, da cotação da neteconomia, mas porque o fechamento no cibermundo começa a ser sentido como um incômodo. No começo, o cibermundo aparecia como um universo sem fim, informal, imaterial e, logo, sem limites. Hoje, sabemos que existem limites, os quais são agora percebidos como asfixia, como condicionamento. Dou um exemplo: pediram-me, recentemente, para definir internet; fiz uma brincadeira, dizendo que não se deve confundir o serviço nacional de informação com a Sorbonne.

\section{RF - Como assim?}

Virilio - O serviço nacional de informação é o serviço secreto que se ocupa de saber tudo sobre a população francesa, e outras, para evitar problemas de subversão política e coisas do gênero. Não se deve, portanto, tomar algo que é da ordem de uma agência nacional de informação, do controle, pela Sorbonne, isto é, pelo cérebro global. Uma coisa é a biblioteca de Babel, de Borges; outra, o cérebro global. Muita gente se iludiu pensando que a internet era esse cérebro global, um cérebro único, o plaeneta como se fosse um enorme cérebro, com o nascimento da unidade mental do gênero humano. Isso acabou. As pessoas já compreenderam que isso era, realmente, uma ilusão.

RF - Há quem diga que o virtual é o nãolugar, portanto a utopia. Como o senhor analisa essa assimilação?

Virilio - Não. O virtual é a atopia. A utopia é Morus, Campanella, as cidades utópicas, uma ilha, um lugar. A utopia é um lugar.

Um lugar ideal onde se tenta a aventura da unidade, da justiça, da unidade da beleza, da verdade, etc. É uma espécie de "cidade santa", mesmo se é laica, onde se busca a realização do ideal. A atopia é a ausência de lugar. Efetivamente, a internet, o cibermundo, é atópico, sem lugar, sem território. Não se trata apenas de uma atopia territorial, mas também corporal, o que a torna mais grave. É um não-lugar e um não-corpo. Sou um homem do corporal. Creio em três corpos: o do planeta (ecológico); o corpo territorial (planeta), sem o qual não há corpo social (a espécie humana); sem corpo social, não há corpo animal, de homem ou de mulher. Sou um homem de três corpos. Por isso, sou urbanista. Ora, a atopia da internet é uma atopia em relação ao corpo territorial, ou seja, a geografia e a geopolítica, ao corpo social - a comunidade virtual não tem realidade física - e, enfim, talvez o mais grave, em relação ao corpo humano, ao corpo animal, no sentido de anima, a alma, não apenas no sentido biológico do termo. Assim, da mesma forma que se inventou o S.O.S depois do acidente do Titanic, pelo qual se clamava "salvem as nossas almas", a internet verá, sobretudo com a informática genética, de decodificação informática do código genético humano, a generalização do "salvem nossos corpos".

RF - O senhor concedeu uma entrevista, transformada em livro, chamada Internet, a 
política do pior, na qual a crítica da técnica é levada ao extremo. Afinal, qual é a política do pior?

Virilio - É muito simples. Antes de tudo, o título não foi escolhido por mim para essa entrevista. Isso nos remete à cibernética. Eu sou um homem profundamente democrático e preocupado com a liberdade, pessoal e social. Creio na cidade, no cidadão, na democracia. Ora, a cibernética é a própria tirania, a maior de todas. Norbert Wiener, quando inventou a primeira cibernética, avisou: "Atenção, é preciso evitar a cibernética política, pois ela é pior do que Hitler". É pior do que todos os tiranos. Orwell esboçou, em sua ficção, os traços dessa tirania inusitada. Quando falo do pior, significa que existe o risco - não passa de um risco, por isso aceitei o título - do fim dos direitos e das liberdades públicos. Existe a possibilidade de uma tirania inigualável, uma tirania tecnocientífica capaz de, ao mesmo tempo, controlar o corpo humano, o corpo social e o planeta. A cibernética está em condição de controlar os três corpos, ou seja, de criar uma tirania diante da qual o nazismo não passaria de um brinquedo, uma antecipação artesanal.

pior é a cibernética social, o darwinismo, pois atrás da cibernética está a eugenia, a possibilidade, graças à decodificação do código genético, de "melhorar" o homem e de chegar ao super-homem. Não se pode separar informática, genética e cibernética. Se estamos, hoje, trabalhando com a clonagem e quimeras em nível de biotecnologia, é por termos a informática para decodificar a extraordinária complexidade do DNA e do código genético humano. Logo, tudo está ligado. Não sou contra a técnica, tanto que em minha escola ajudei a implantar e desenvolver a internet, convidei Nicholas Negroponte, quando eu era diretor da escola especial, há 20 anos, para dar conferências e sempre procurei aproveitar o melhor do desenvolvimento tecnológico. Mas sou contra a ilusão. Eu sou contra a promoção publicitária dessa ilusão.

RF - Justamente, qual é a sua opinião, mais detalhada, sobre os que como Nicholas Negroponte e Pierre Lévy fazem uma espécie de divulgação publicitária da internet e das novas tecnologias da comunicação?

Virilio - Conheço bem Pierre Lévy e fiquei muito decepcionado com a sua atitude em relação a mim. Lévy escreveu coisas injuriosas sobre mim, de fato escandalosas, que meus amigos, a quem algumas delas foram submetidas, recusaram-se a publicar, de tão violentas que eram. Não quis entrar na polêmica, pois eu o estimava e surpreendeu-me o seu lado guru da internet, um aspecto sectário que eu, até então, desconhecia nele, como se não fossêmos livres para criticar a internet. Que significa isso? Somos livres para ser contra ou a favor.

Quando

um homem me diz que prefere certa interpretação musical, não o acuso de ser racista, enganador ou algo assim. Digo que tem outra inteligência, outra sensibilidade para, por exemplo, Mozart ou um pintor. Eu sou um homem livre e considero que somos todos livres para ter expectativas em relação à internet. Por isso, não admito a violência manifestada por Pierre Lévy contra mim. Acho que ele se deixou, infelizmente, arrastar para o terreno do delírio, um delírio de interpretação nefasto a respeito da cibernética e de temas adjacentes. Com isso, Lévy desperdiça o seu talento. Quanto a Negroponte, ele fez um importante trabalho inicial, no MIT, criando o Architecture Machine Group. As suas pesquisas sobre informática no MIT começaram no campo da arquitetura, com aplicação em programas para cidades, urbanismo e questões semelhantes, e por isso o convidei para palestrar na França. Depois, tornou-se o nome que se conhece agora, tendo chegado à criação de Wired. Foi um ótimo trabalho. Hoje, ele não me conhece mais e afirma que nunca me encontrou. Não compreendo. 
Que significa essa censura? Há uma única coisa nele que me sinto obrigado a contestar: dizer que os bits substituem os átomos. É o tipo de argumento publicitário por excelência sem base alguma na realidade. Os átomos existem, assim como os bits de informação e outros também existem, pois a matéria é composta de três elementos: a massa, a energia, a informação. Não estou inventando isso, é a física quem o diz. Assim, a matéria é formada pela massa, por átomos, por energia e por informação. Por que, mais uma vez, apostar no darwinismo e dizer, de forma aberrante, que os bits substituirão os átomos? Isso me remete para idéias como as de que o super-homem substituirá o homem, os arianos substituirão os judeus, os brancos substituirão os negros, etc. Isso se chama racismo. Por trás disso, há uma intolerância fatal que não admito. Os bits coexistem com os átomos; os brancos, com os negros; os arianos, com os nãoarianos... Há nisso uma forma de eugenia, de darwinismo, que é a imposição da eliminação, da substituição, da exclusão. Não se elimina nada disso, coloca-se ao lado, faz-se coexistir.

RF - Há quem diga que o senhor, assim como outros intelectuais franceses, entre os quais Lucien Sfez, faz discursos muito interessantes e críticos, por exemplo, a respeito da internet, mas sem qualquer demonstração. Qual é o verdadeiro perigo, concreto, cotidiano, da internet? Como é que ela vai aprisionar as pessoas?

Virilio - Antes de tudo, a demonstração está sendo feita pelo e-crack, pelo crack da neteconomia, pelo bug do ano 2000, que de fato aconteceu, está sendo feita também pela multiplicação de sites terroristas na internet. A demonstração está sendo feito não por mim, mas por acidentes. Ocorre que desenvolvo uma "teoria do acidente", tanto que meu próximo livro tratará disso. Significa que uma técnica existe não apenas pela monstração - a publicidade, a propaganda, a promoção - , mas também pela demonstração, ou seja, pelo fracasso, pela derrota, pelo acidente. Em outras palavras, o acidente é a demonstração dos limites de uma técnica. Quando se inventa o navio, inventa-se também o naufrágio. Não é preciso demonstrar que o navio afunda. Isso se faz por si. A demonstração não é feita por Arquimedes, que explica os problemas de um sólido na água, mas pelo acidente do Titanic, do Concorde. A internet é um novo objeto informacional que tem a potência de inaugurar o seu acidente. Cada técnica tem o seu acidente. A eletricidade possui a eletrocução ou Chernobyl. Na época da ecologia, do princípio de precaução, do recuo diante da ilusão da técnica e da ciência, os acidentes são elementos muito importantes para analisar, sobretudo quando se trata de uma tecnologia emergente. A demonstração que interessa não é a minha, mas a dos fatos. Um acidente é um fato. Mais do que isso: uma derrota. Citei alguns acidentes, assim como falei bem antes do bug do ano 2000 e do crack da nova economia, para espantos de muitos, do que poderia acontecer. Não sou um profeta. Digo apenas que há nessa nova técnica uma potência de acidente incomparável, uma possibilidade extraordinária de condicionar o mundo de imediato. A característica da internet e da cibernética é de condicionar o tempo à escala do mundo. Falo de potência. Mas já estamos quase lá. Se amanhã todos estiverem conectados, o acidente da internet será integral. Ou seja, desencadeará acidentes em cadeia. Já tivemos exemplos com os vírus, com o bug, com a neteconomia, a Nasdaq. Sou um experimentalista e acompanho os fatos. Não sou um teórico da informática. A minha teoria é a velocidade. Sou um dromólogo. Trabalho com a questão da aceleração. Mas observo o nascimento de acidentes gerais. Ainda um exemplo: quando se inventa o navio, ele afunda num determinado lugar. $O$ Titanic afundou no Atlântico Norte ao chocar-se com 
um iceberg. Sabe-se o lugar, a latitude, a longitude, tudo. Quando Chernobyl explode, isso se dá num lugar, em Chernobyl, contaminando Kiev e uma parte da Europa. Até agora todos os acidentes eram específicos e locais. Eram relativos a um determinado objeto, num determinado lugar, num determinado momento. Eram acidentes particulares. Todas as invenções, mesmo as maiores bombas, inclusive a atômica, só produziam acidentes locais. Falo de uma bomba, não de dez mil. Falo da destruição de Hiroshima. O próprio da cibernética é a unidade de tempo e de espaço da interação, de modo que o acidente da internet, logo da cibernética, é geral, passível, potencialmente, de atingir todos e tudo ao mesmo tempo, no mesmo instante. Os meus críticos alegam que isso nunca existiu. Sim, mas antes da invenção da jangada não havia naufrágio. Foi preciso inventá-la para ver que podia afundar. Estamos diante de algo emergente. Porém, não sou o teórico que descreverá por antecipação o acidente integral. Digo apenas que, em potência, ele está aí. Já apareceram sucessivas confirmações, não para dizer que tenho razão, mas mostrando que o fato internet possui o seu acidente. Muitos tentaram me fazer passar por um ludista, um antimodernista, o diabo. Sinto muito, trabalho com a técnica e a ciência há 25 anos, amo a arte da técnica, só trabalho com isso, e dizer que sou contra é difamação e mentira.

RF - Apesar de tudo isso, muitos dos seus críticos o consideram apocalíptico e exagerado em relação aos efeitos negativos concretos da tecnologia?

Virilio - Adoro a técnica. Tudo isso que dizem é totalmente falso. $O$ apocalipse é a revelação. A palavra apocalipse não diz respeito ao fim do mundo, mas à revelação.

Efetivamente, a internet é reveladora da mundialização, da globalização. Sem a internet, sem a informática, não haveria globalização. Logo, mais uma vez, tenta-se, com essa palavra, desqualificar-me.

Não se quer entrar na discussão, na inteligência da técnica, na argumentação, mas deslegitimar-se alguém com quem não se concorda.

Diz-se apocalíptico como quem diz racista, fascista, chauvinista, etc. Não sou nada disso. Basta ler meus livros para que tudo se esclareça.

RF - Inventa-se a jangada, ela afunda, pessoas morrem. Inventa-se a eletricidade, há eletrochoque, pessoas sofrem. Inventase a energia nuclear, há radioatividade, isso contamina, pessoas adoecem e morrem. Qual é o acidente da internet com conseqüência tão graves como essas?

Virilio - O acidente integral da internet está ligado ao desenvolvimento da internet. Mais uma vez, o que me interessa são os fatos, não as teorias. Por isso, vamos ao exemplo. Admitamos que amanhã o mundo inteiro, ao menos o desenvolvido, pois não me refiro aqui ao Terceiro Mundo, esteja conectado. De outra maneira: somos seis bilhões no Planeta; digamos que dentro de uma geração, ou seja, uns 20 anos, existam quatro bilhões de internautas, que o mundo inteiro, grosso modo, esteja na rede. É evidente que nesse estágio, o menor acontecimento na internet, acidental, diz respeito ao mundo inteiro, no mesmo instante. O que é a interatividade? Eu disse, em A Bomba informática, que a interatividade está para a informação assim como a radioatividade está para a energia. A interatividade é a base da cibernética da internet. Mesmo se, neste instante, ainda não estamos no limite, a rapidez dos contatos entre os indivíduos, os portais, os motores de busca, tudo isso ainda é lento, mas a tentação, isto é, o objetivo da internet é de atingir a interatividade máxima. Isso significa desenvolver a bomba informática; em outras palavras, se o acidente é positivo, ele é multiplicador; se é negativo, ele é multiplicador e finalizador ao mesmo tempo. A única imagem aproximada desse fenômeno é o crack econômico, pois a economia consiste em informação. 
Podemos lembrar os cracks de 1929 e de 1987. O sistema financeiro é um fenômeno de informação e de velocidade. A partir do momento em que as bolsas funcionam com a cotação automática de valores, chegamos à possibilidade de uma quebra instantânea em todos os lugares, em todas as bolsas. Foi o que aconteceu em 1987, com o bigbang de Wall Street e da City, em Londres, aos quais se ligavam outros pontos de investimento em bolsa.

No dia em que todos os bancos e bolsas do mundo estiveram interconectados, o crack será necessariamente mundial. Enfim, não quero me defender das opiniões dos outros sobre isso, pois não ataco. Mas, depois de ter apresentado meus argumentos, observo que existe uma espécie de intolerância à contradição feita de injúrias. Acusam-me de ser apocalíptico e retrógrado; não me interessa mostrar que não o sou. Basta-me destacar fatos e desenvolver argumentos.

RF - A maioria dos internautas usa a rede para comunicar, não para fazer negócios. Que acidente pode acontecer quando se trata apenas de estabelecer comunicação com outras pessoas?

Virilio - A possibilidade de um controle social que ultrapassa amplamente $o$ da polícia e o dos serviços secretos. Sabemos muito bem que com a internet, com o telefone celular e com a eletronização da vida, o controle aumenta. Já não podemos separar internet, televisão e telefone. Não é por acaso que as multinacionais se interessam por esses três mercados. A cibernética é o todo, e a internet nada é fora da bolha cibernética em desenvolvimento. Essa bolha tem uma possibilidade de controle social terrível, quase cósmica. Mais uma vez, não devemos confundir os serviços de informação com a Sorbonne.

RF - Há muitos que vêem a internet como o espaço da liberdade e da anarquia.

Virilio - É completamente falso. A internet é a anarquia junto com as multinacionais; estas necessitam de anarquia. Elas, tão potentes, precisam de que inexista ordem.

É o lobo no meio do rebanho. A ausência de autodefesa, a fragilidade dos outros, tudo isso favorece os poderosos que dominam a rede. Nesse sentido, a anarquia é o aliado da tirania. Entre os gregos, a anarquia social, a decomposição da sociedade, funciona como estribo para a tirania. Não sou contra a internet, mas contra os que dizem que ela é libertária, sendo o cibermundo o espaço de uma vida livre se sem lei.

Isso é bobagem. É uma mentira, um abuso de linguagem.

RF - Para a mídia, o bug do milênio não aconteceu, sendo quase uma frustração. O senhor afirma, ao contrário, que ele se realizou. Por quê?

Virilio - Claro que aconteceu, de outra forma. Ele foi barrado por investimentos poderosos e custou em torno de 400 bilhões de dólares no mundo inteiro. Sabiase a data do acidente e as empresas puderam realizar a custosa troca de programas que evitou a catástrofe. Houve a antecipação que impediu o mal. Mas estamos diante de uma realidade negada. Como pode algo que custou 400 bilhões de dólares não ter existido? Há coisas que me irritam e das quais eu não deveria falar mais, dado que se perde tempo, entre as quais o crack da neteconomia e o bug do milênio, coisas que sinalizam claramente o perigo do acidente total dissimulado pelos publicitários das novas tecnologias. Repito: sou um experimentalista. Antes de fazer teorias, devemos observar os acontecimentos. Nisso reside a inteligência científica. Compreender os aspectos negativos da técnica serve ao seu próprio desenvolvimento e à sua utilidade social. Precisamos civilizar a internet. A anarquia nunca foi a civilização. Sempre foi a guerra de todos contra todos e a vitória do mais forte. Ninguém me aplicará o golpe da bela 
anarquia. Conheço isso e não caio.

RF - Muito se tem falado de uma mudança civilizacional com o advento da internet. Isso implica aspectos positivos mas também negativos. Essa transformação é real?

Virilio - Desde o começo do século XIX, no Ocidente, paira a ameaça da perda da civilização. A barbárie espreita. A Europa, com as guerras mundiais, a bomba atômica e o holocausto, foi o lugar da barbárie e da possibilidade do fim do mundo. Entre Auschwitz e Hiroshima há a possibilidade do fim de uma civilização. O Ocidente, em geral, incluindo os Estados Unidos, desencadeou uma possibilidade de fim de um mundo, de uma civilização. Por tudo isso, não me deixo iludir pela civilização da internet quando conheci o horror da Segunda Guerra Mundial e vivi a época dos campos de concentração. Pertenço à era da bomba atômica e da dissuasão nuclear, ou seja, ao fim do mundo, portanto, quase aos 70 anos, não posso crer em mudanças de civilização tão pouco demonstradas.

RF - O senhor é um homem de esquerda. Existe um futuro melhor para a humanidade? A técnica será um instrumento dessa melhora?

Virilio - Eu sou um democrata, de esquerda, mas antes de tudo um democrata. Não creio no socialismo utópico, no qual, de resto, nunca apostei. Nunca fui membro do Partido Comunista Francês, nem mesmo do Partido Socialista. Sou cristão. Não sou sensível à utopia socialista. Sou sensível à necessidade de justiça social para garantir a paz civil, sem a qual não existe democracia.

A democracia tem dois inimigos, um dos quais é sempre esquecido: o tirano, que se opõe à democracia, e a anarquia, a guerra de todos contra todos, a metástase social. Conhemos tantos tiranos, de Stalin a Hitler, de Mussolini a Fidel Castro, e, do outro lado, o que é novo, a possibilidade da anarquia, de uma guerra civil geral.

RF - Qual é o sistema social dos seus sonhos? Em outras palavras, qual o seu projeto para a sociedade de amanhã? Há brasileiros que olham a social-democracia francesa com uma certa inveja. Há franceses que, durante a realização do Fórum Social Mundial, em Porto Alegre, vibraram com a perspectiva utópica de algumas correntes da esquerda brasileira. Quem está com a razão?

Virilio - Sonho com a reinvenção da justiça social dentro da democracia Como já disse, não acredito nas utopias políticas ou tecnológicas. O sovietismo desapareceu com a queda da União Soviética. A utopia comunista, plasmada no socialismo dito real, foi um pesadelo. Entre os séculos XIX e XX as utopias coletivistas experimentaram apogeu e decadência. Agora, a construção da justiça social democrática terá de ser feita fora dos mitos dos dois últimos séculos. De nada adiantará importar as teorias do século $X X$, as práticas de organização social do século XIX ou as pretensões cientificistas de um certo marxismo de 40 anos atrás. Tudo isso morreu com a queda do muro de Berlim, com o fim da ilusão do socialismo não-democrático e com a descoberta do fracasso da experiência soviética.

Há um trabalho de reconstrução da justiça social a ser feito, em torno da noção de ecologia, não somente da ecologia tradicional, mas da ecologia cinza. Eu me explico. No momento da Rio 92, a reunião sobre os destinos do Planeta, a qual, mesmo convidado, não pude comparecer, gravei um vídeo que o governo francês enviou para o encontro. Nele, indiquei que existem duas ecologias, a verde, de substância, do ar, da água, da fauna, da flora, e outra, cinza, sem cor, de distância. À poluição da natureza, grande ameaça para o homem, junta-se a poluição de grande dimensão, ou seja, a poluição da distância entre os homens, 
entre os países que habitamos, pois o homem não habita apenas o ar, a água, as pedras, mas também distâncias. $\mathrm{O}$ homem não tem 170 metros de altura, mas, por exemplo, $1 \mathrm{~m} 70 \mathrm{~cm}$. Por quê? Porque faz parte do universo de proporções, no qual as casas têm uma dimensão, as relações entre os homens, outra, etc. Ocorre que a rapidez das novas tecnologias esmaga as distâncias tradicionais. A compressão temporal é uma poluição das grandes dimensões naturais.

Trata-se de um fechamento que, em breve, tornará insuportável a convivência entre os seres. Não haverá mais espaço físico nem temporal separando as pessoas. A cibernética e as viagens supersônicas comprimem o mundo como numa prisão cujas paredes se movessem diminuindo 0 espaço existente. Isso também faz parte da ecologia da existência e deve ser incorporado nos projetos de construção de justiça social na democracia, ou seja, superar o efeito de prisão suscitado pela compressão do tempo e do espaço. Por isso, sou contra a ilusão da interatividade, que é somente a oposição de todos contra todos, uns contra os outros no imediatismo da comunicação telefônica ou virtual, como se estivéssemos num submarino, onde os homens se odeiam, pois estão muito próximos, quase não há separação entre eles, inexiste espaço para a socialidade. Os animais, num zoológico, não se reproduzem, pois Ihes falta a grande dimensão do espaço natural, as distâncias entre os sexos, as espécies, os seres, próprias do habitat animal, assim como do humano. A nova justiça social deverá considerar não apenas a partilha da riqueza - isso fazia o socialismo - , mas também da divisão das riquezas ecológicas, da água, da energia, das substâncias necessárias à existência em comum. Hoje, privatiza-se a água; amanhã, o ar. Não. Isso é patrimônio comum. Não podemos aceitar de pagar para respirar. Privatizar significa dizer quanto se pode consumir. Você já respirou demais para o seu capital.
Pare de respirar. Não. É inaceitável. Ou teremos um contador de ar no pescoço. Parece bobagem, mas já vivemos a guerra da água. Para entender isso não podemos nos servir nem de Marx nem de Proudhon, nem de Kant nem de Nietzsche, nem de Platão nem Hegel. Precisamos ser os novos intérpretes desse novo mundo. Devemos construir uma nova justiça para a democracia mundial. Há um trabalho de criação a realizar, para o qual não existem mestres, apenas interlocutores.

RF - Para o senhor, então, o problema das novas tecnologias não é de produzir isolamento e fragmentação, mas possivelmente o contrário, excesso de unidade e de proximidade?

Virilio - As novas tecnologias - a internet, por exemplo - provocam concentração, eliminação da separação entre os seres. Conheci McLuhan, em companhia de Jean Duvignaud, que era um discípulo de Rousseau. Para McLuhan, havia uma espécie de idealismo da aldeia global. Era um ingênuo. Ele foi importante, mas ingênuo como os pioneiros, que têm a potência da criação de um mito, sem o distanciamento necessário para a análise do fenômeno gerado. Tudo é bom, belo e feliz. As novas tecnologias ajudam a produzir a aldeia global da asfixia por falta de espaço.

RF - Urbanista e arquiteto, o senhor tornou-se filósofo. Por quê?

Virilio - Não sou filósofo. Na verdade, sou um homem de concentração, de reflexão sobre os espaços urbanos, as cidades, marcados pela concentração. Trabalhar com a cidade significa trabalhar com o espaço e o tempo, logo com a velocidade. Com a revolução industrial e com a revolução dos transportes, as cidades tornaramse caixas de velocidade. As residências não alojam apenas homens, objetos, produtos, pessoas, mas proximidade social, 
interferências, dimensões energéticas. Com as novas técnicas de transmissão - do rádio à internet - só se aumentou a velocidade de contato.

Ser urbanista hoje exige uma inteligência dromológica, capaz de compreender a velocidade e a aceleração. Em grego, dromos significa corrida. A palavra rua está na raiz corrida, como dromos. Ser urbanista implica compreender que a cidade é traçar, povoar, construir, pôr em movimento. Tenho refletido sobre a importância da velocidade nas cidades e nas relações sociais. Para isso, estabeleci a dromologia, a disciplina que estuda a velocidade como meio político. Ao lado da economia política da riqueza, da economia, do capitalismo, há a economia política da velocidade. Riqueza e velocidade são as duas faces da economia.

Não há só riqueza - propriedade de bens -, mas também velocidade - a aceleração do vivido. Meu trabalho é de urbanista contemporâneo, da época da aceleração e da invenção da velocidade da ruptura da barreira do som, da barreira do calor - velocidade de liberação, 20 mil $\mathrm{k} / \mathrm{h}$ para colocar um satélite em órbita - e, por fim, a ruptura da barreira orbital - $40 \mathrm{mil} \mathrm{k/h}$ para sair da órbita planetária. O mundo moderno vive a revolução da aceleração. Não posso estar alheio a ela. Chegamos à velocidade absoluta, a da luz, na cibernética, pela qual ondas eletromagnéticas, ainda que custe caro, podem estabelecer relações interpessoais na velocidade da luz. A cibernética tende para a criação do live por tudo e para todos. É isso a interatividade. É a tensão, a perspectiva, da criação de algo inacreditável, para o qual as sociedades antigas não estavam preparadas, pois só conheciam velocidades relativas, como a do cavalo, por exemplo, tendo a invenção da cavalaria sido uma revolução. Basta examinar a conquista da América para ver a importância do cavalo nesse acontecimento histórico. A conquista foi feita pelos cavalos, não pelos homens. Mesmo a revolução industrial e de transportes baseia-se nas velocidades relativas, da máquina a vapor, do motor de explosão, etc. Da corrida de cavalos, da dromocracia, até agora estávamos na velocidade relativa.

Com a revolução da velocidade da luz, da cibernética, da informática, da telemática, chegamos à velocidade absoluta. Pela primeira vez na história, o homem toca um limite cósmico. Não é mais o limite da superfície terrestre, dados que vamos à lua, mas o cósmico. Esse fenômeno exige, para ser compreendido, uma economia política da velocidade, um complemento à economia política da riqueza elaborada por François Quesnay e os fisiocratas. Eu sou uma espécie de fisiocrata urbanista que fala da necessidade dessa economia política da velocidade, de onde a rejeição à cibernética. $A$ velocidade da luz não pode tornar-se uma fatalidade terrorista.

RF - O senhor pensa que se pode de fato mudar algo. Às vezes, parece que a sua análise não deixa brechas para a transformação.

Virilio - Não quero impedir nada. Quero influir. Penso que tudo pode ser pensado, alterado, considerado. Não peço a eliminação da internet e da cibernética. Exijo que elas sejam civilizadas. Os homens sobreviveram à pré-história porque inventaram meios para escapar aos dinossauros. Não existe progresso sem uma análise experimental dos seus prejuízos. Portanto, estudo os problemas do progresso. Não tento evitá-lo. Sempre gostei da velocidade, de moto ou carro, e soube praticá-la. Quando estamos em cima de uma moto, precisamos saber angular. Cada vez que se acelera, devese saber buscar a angulação adequada. Numa corrida de motos, cada piloto busca o ângulo nas curvas, joga o corpo para um lado, para outro, toca no chão, procura a inclinação certa. Com a reflexão, é o mesmo.

Hoje, devemos buscar o ângulo certo para olhar a informática, a internet, as 
novas tecnologias.

\section{terceiro crime contra a humanidade}

$\mathrm{O}$ atentado terrorista que atingiu os Estados Unidos da América, em 11 de setembro de 2001 e abalou o mundo, colocou Paul Virilio no centro de uma polêmica intelectual que atravessou fronteiras.

O pensador francês, num texto de 1993, antecipou a possibilidade de um ataque total contra o World Trade Center.

Tornou-se necessário ouvir Virilio novamente para completar esta entrevista que chegou a ser ultrapassada pela confirmação, na prática, das idéias do entrevistado. Um raro caso de obsolescência exitosa.

RF - O atentado ao Pentágono e ao World Trade Center pode ser visto como o primeiro acidente total da era da globalização?

Virilio - Sim. É o prenúncio do que poderá acontecer a partir de agora. Em 20 de março de 1993, depois do primeiro atentado contra o World Trade Center, como arquiteto que sou, denunciei a possibilidade de um ataque total para derrubar as duas torres. Fui chamado de apocalíptico e de pessimista. Publiquei sobre isso, primeiro, um artigo no hoje extinto jornal Globe. Depois, lancei um livro, Un paysage d'Evéne-ments, cujo terceiro capítulo, "Nova York delira", prevê o tipo de atentado que acabou por ser realizado em 11 de setembro de 2001.

RF - Quais eram os indícios?

Virilio - É importante dizer, antes de tudo, que o atentado que destruiu o World Trade Center tem o mesmo grau de importância que a explosão da bomba de Hiroshima. O mundo nunca mais será o mesmo depois disso. Por que pude antecipar o acontecimento? Por defender que entramos na era da terrorismo global, sem fronteiras, de um novo tipo, com estratégias novas e fatais. Busca-se o efeito surpresa, o máximo de desgaste e o menor custo possível. A visibilidade das torres do WTC, associada à fragilidade delas, só poderia estabelecer um alvo especial. Seja qual for o material desse tipo de construção - aço, concreto, vidro -, não há como suportar um impacto de intensidade multiplicada pela velocidade de um objeto. O terrorismo globalizado aposta no cruzamento da alta eficácia com custo reduzido.

RF - Não é um exagero comparar esse atentado com Hiroshima?

Virilio - Não. Hoje não existem mais pessimistas e otimistas. Só realistas e mentirosos. Eu sou um realista. Os atentados de 11 de setembro de 2001 introduziram a possibilidade real de atentados nucleares e com armas químicas e biológicas. Com Hiroshima, ultrapassouse um limite. Com a derrubada das torres do WTC, superou-se outro estágio. Entramos numa nova forma de guerra civil. Neste caso, deve haver em torno de cinco mil mortos como resultado da transformação de um meio de transporte em arma. Não é possível construir torres que funcionem como bunkers. Assim, as construções que deviam abrigar tornam-se armadilhas.

RF - Como será o mundo depois da superação desse limite?

Virilio - O mundo tinha conhecido dois crimes contra a humanidade: Auschwitz e Hiroshima. O atentado ao World Trade Center é o terceiro crime contra a humanidade. Não falo do ataque ao Pentágono. Caso a ação terrorista tivesse se limitado a destruir o Pentágono, o mundo teria rido, pois se trataria de um golpe contra uma máquina de guerra. Não se pode separar o simbólico e o concreto nisso tudo. Os terroristas enfrentaram o poder militar, que é o Pentágono, mas 
produziram o maior efeito ao destruir o coração econômico e civil dos EUA. O humano foi abolido. Pode-se imaginar que se multiplicarão os ataques suicidas. O exemplo sempre produz seguidores. O mundo entra numa lógica de guerra. Mas não se trata mais da guerra convencional. Agora se está numa dinâmica insidiosa de guerra civil e pelo terror.

RF - Quais as causas dessa aceleração? Há quem sustente se tratar de uma nova fase da luta entre ricos e pobres?

Virilio - Bobagem. Quem diz isso não sabe do que fala. A luta de classes nada tem a ver com esse novo fenômeno. Os velhos esquemas não podem explicar esse novo objeto. O marxismo está fora disso como horizonte de explicação. É preciso ser claro: o marxismo deu conta genialmente do século XIX. Não entendeu nada do século $X X$. E será inútil no século $X X I$. Digo isso com a consciência tranqüila, pois sou um homem de esquerda. Não respaldo o reacionarismo de George W. Bush, interessado em transformar tudo numa guerra da civilização contra a barbárie, nem o simplismo de quem pretende fazer disso uma guerra de religiões ou uma resposta dos excluídos aos opressores.

RF - Como se explica, então, os acontecimentos que chocaram o mundo?

Virilio - É uma guerra sem referências. O inimigo pode ser designado, mas não é explícito. Bin Laden, por mais suspeito que seja, pode encobrir situações mais complexas. O pior estaria sempre num confronto com o Iraque. De toda maneira, o problema do Oriente Médio atravessa o dilema posto à comunidade internacional. A solução terá de ser mais política do que militar.

RF - O imaginário cinematográfico também antecipou o atentado?
Virilio - Os filmes de catástrofe seguem a evolução da técnica e os indícios da realidade. Por isso, previram a estética da nova guerra. Saímos da guerra substancial, convencional, inadequada aos atores em confronto, e entramos na guerra acidental, civil, marcada por um conflito entre homem e máquina. Os atentados de 11 de setembro podem ser vistos com o crack do pentágono, da mesma forma que aconteceu antes o crack da netecononomia.

$\mathrm{Na}$ época da tecnologia mais avançada, com armas nunca antes imaginadas, um homem pode matar milhares de pessoas jogando um avião sobre um prédio. Não estamos na ficção científica nem na simulação, mas nas estratégias de inteligência.

O cinema pode representar esse imaginário, mas o essencial está numa produção espetacularizada voltada para a mídia. O terrorismo precisa gerar efeitos de disseminação midiática. Com a derrubada das torres do WTC, o terrorismo global teve o seu primeiro instante midiático total.

RF - Tudo isso pode ser resumido como uma reação antiamericana? Ou, em outras palavras, a emergência de um imaginário antiamericano?

Virilio - Insisto: não se trata de um conflito entre barbárie e civilização, nem de fanáticos contra democratas. Mas do surgimento de uma nova forma de expressão violenta.

O império sempre atrai ódio. Não poderia ser diferente com os Estados Unidos, que, além do mais, disseminam através de tecnologias de contato um imaginário capaz de influência global. Ainda assim, o antiamericanismo não explica tudo.

Precisamos de tempo para refletir e construir instrumentais analíticos aptos a decifrar o novo enigma. A opção por explicações causais simples pode levar ao pior. Por exemplo, a uma nova guerra mundial. Não se deve esquecer que um atentado em Sarajevo detonou a Primeira Guerra Mundial. As mudanças impostas 
pelo terror global superam as medidas de

curto prazo. A dúvida se impõe .

\section{Nota}

Entrevista concedida a Juremir Machado da Silva. 